\title{
Novel biomarkers for the diagnosis and prognosis of colorectal cancer
}

\author{
Hyung-Hoon $\mathrm{Oh}^{1}$, Young-Eun $\mathrm{Joo}^{2}$ \\ ${ }^{1}$ Department of Internal Medicine, 3rd Fleet Medical Corps, Republic of Korea Navy, Yeongam; ${ }^{2}$ Department of Internal Medicine, Chonnam \\ National University Medical School, Gwangju, Korea
}

Colorectal cancer (CRC) is among the most common malignancies and remains a major cause of cancer-related death worldwide. Despite recent advances in surgical and multimodal therapies, the overall survival of advanced CRC patients remains very low. Cancer progression, including invasion and metastasis, is a major cause of death among CRC patients. The underlying mechanisms of action resulting in cancer progression are beginning to unravel. The reported molecular and biochemical mechanisms that might contribute to the phenotypic changes in favor of carcinogenesis include apoptosis inhibition, enhanced tumor cell proliferation, increased invasiveness, cell adhesion perturbations, angiogenesis promotion, and immune surveillance inhibition. These events may contribute to the development and progression of cancer. A biomarker is a molecule that can be detected in tissue, blood, or stool samples to allow the identification of pathological conditions such as cancer. Thus, it would be beneficial to identify reliable and practical molecular biomarkers that aid in the diagnostic and therapeutic processes of CRC. Recent research has targeted the development of biomarkers that aid in the early diagnosis and prognostic stratification of CRC. Despite that, the identification of diagnostic, prognostic, and/or predictive biomarkers remains challenging, and previously identified biomarkers might be insufficient to be clinically applicable or offer high patient acceptability. Here, we discuss recent advances in the development of molecular biomarkers for their potential usefulness in early and less-invasive diagnosis, treatment, and follow-up of CRC. (Intest Res 2020;18:168-183)

Key Words: Biomarker; Diagnosis; Prognosis; Prediction; Colorectal neoplasms

\section{INTRODUCTION}

Colorectal cancer (CRC) is a leading cause of cancer-associated morbidity and mortality worldwide. ${ }^{1}$ Despite evidence of a 5-year survival rate of $90 \%$ when CRC is diagnosed at an early stage, less than $40 \%$ of cases are diagnosed when the cancer is still localized. ${ }^{1}$ Most CRC cases develop from precursor lesions defined as adenomatous polyps. ${ }^{2}$ Currently available screening programs for CRC are administered using guaiac-based fecal occult blood tests, fecal immunohistochemical test, flexi-

Received July 5, 2019. Revised September 5, 2019.

Accepted October 24, 2019.

Correspondence to Young-Eun Joo, Department of Internal Medicine

Chonnam National University Medical School, 42 Jebong-ro, Dong-gu,

Gwangju 61469, Korea. Tel: +82-62-220-6296, Fax: +82-62-225-8578,

E-mail:yejoo@chonnam.ac.kr ble sigmoidoscopy, or colonoscopy. Colonoscopic polypectomy is an effective screening and prevention modality for detecting and treating precancerous and early cancerous lesions to decrease CRC incidence and mortality rates. ${ }^{3}$

Rapid advances in our understanding of the molecular and biological characteristics of CRC have provided useful knowledge about its pathogenesis. ${ }^{1,2}$ It has become possible to the develop biomarkers that help with the identification of patient responses with respect to cancer diagnosis, management, and surveillance. ${ }^{4,5}$ The identification of biomarkers that can aid CRC early detection or monitoring would enable the development of personalized medicine and improve survival rates.

An ideal CRC biomarker should be easily and quantitatively measured, highly specific and sensitive, reliable, and reproducible. It should also be able to differentiate between differ- 
ent risk-based populations and select patients who require a second-line test (endoscopic and radiologic investigations). Ideally, these aims can be achieved with a noninvasive and inexpensive method using easily available biological samples such as urine, breath, serum, or feces. ${ }^{6-9}$ Despite advances made in recent years, no single test is currently able to diagnose and monitor the posttreatment course of CRC patients. Here, we review the current status of newer diagnostic, prognostic, and predictive biomarkers in CRC and provide insights for their implementation in clinical management.

Table 1. Summary of Diagnostic Biomarkers

\begin{tabular}{|c|c|}
\hline Biomarker & Explanation \\
\hline \multicolumn{2}{|l|}{ Tissue biomarker } \\
\hline Cytokeratins (CKs) & $65 \%-95 \%$ of CRC cases show a CK7-/CK20+ pattern. ${ }^{10}$ \\
\hline $\begin{array}{l}\text { Caudal type homeobox } \\
2 \text { (CDX2) }\end{array}$ & $\begin{array}{l}\text { Sensitivity and specificity of CDX2 expression in CRC diagnosing is greater than 90\%. As CDX2 expression alone cannot } \\
\text { differentiate among adenocarcinomas of the } \mathrm{Gl} \text { tract, }{ }^{13,14} \text { it is useful as an adjunct to CKs. }\end{array}$ \\
\hline $\begin{array}{l}\text { Special AT-rich sequence } \\
\text { binding protein2 (SATB2) }\end{array}$ & $\begin{array}{l}\text { The addition of SATB2 to standard panels showed no significant improvement in sensitivity or specificity in the diagnosis } \\
\text { of CRC. }{ }^{18} \text { As SATB2 expression was positive in } 95 \% \text { of metastatic CRC and } 0 \% \text { of ovarian carcinoma cases, it could be } \\
\text { useful as a marker to exclude ovarian carcinomas. }{ }^{19,20}\end{array}$ \\
\hline Cadherin 17 (CDH17) & $\begin{array}{l}\text { Cadherins are cell-cell adhesion molecules that play important roles in maintaining tissue structure under normal } \\
\text { conditions. }{ }^{21} \mathrm{CDH} 17 \text { is reportedly expressed in } 96 \%-100 \% \text { of primary and } 100 \% \text { of metastatic CRC. }{ }^{25-27}\end{array}$ \\
\hline Telomerase & $\begin{array}{l}\text { Telomerase is a ribonucleoprotein that maintains telomeres by adding TAGGG repeats onto them. }{ }^{29} \text { Cancer cells bypass } \\
\text { DNA damage-induced inhibitory signaling pathways by upregulating telomerase. Using TBT, telomerase showed } 95 \% \\
\text { sensitivity and 95\% specificity in CRC. }{ }^{32}\end{array}$ \\
\hline GPA33 (A33) & $\begin{array}{l}\text { A33 is expressed in the stomach, small intestine, colon, and rectal epithelial cells. It is expressed in more than 95\% of } \\
\text { human } \mathrm{CRC}^{35} \text { Also, an immunohistological study comparing } A 33 \text { and CDX2 revealed that } A 33 \text { showed similar sensitivity } \\
\text { as but a higher specificity than CDX2 as an immunomarker of CRC. }{ }^{36}\end{array}$ \\
\hline \multicolumn{2}{|l|}{ Blood biomarker } \\
\hline $\begin{array}{l}\text { Circulating cell-free } \\
\text { DNA (cfDNA) }\end{array}$ & $\begin{array}{l}\text { The cfDNA is released as much larger fragments in tumor cells than in normal cells. }{ }^{41} \text { Quantitative analysis of circulating } \\
\text { cfDNAs by measuring the ratio of longer and shorter DNA fragments, in other words, measuring cfDNA integrity } \\
\text { number during the diagnosis of CRC, showed sensitivity of 73\%-90\% and specificity of } 97 \%-85 \%{ }^{42,43}\end{array}$ \\
\hline MicroRNA (miRNA) & $\begin{array}{l}\text { The miRNAs are } 18-25 \text { bp-long small noncoding RNAs that regulate gene expression by binding to mRNA. }{ }^{47} \text { Compared } \\
\text { to mRNA, miRNAs show higher stability in the blood. Different combinations of miRNA showed high sensitivity and } \\
\text { specificity for detecting } C R C^{52,53}\end{array}$ \\
\hline $\begin{array}{l}\text { Long noncoding } \\
\text { RNA (IncRNA) }\end{array}$ & $\begin{array}{l}\text { HIF1A-AS1 showed high diagnostic ability of CRC with an AUC of 0.960. CRC patients with high HIF1A-AS1 expressions } \\
\text { were associated with shorter } 5 \text {-year survival rate than those with low HIF1A-AS1 expression. }{ }^{56} \\
\text { CRNDE-h showed better diagnostic value compared to CEA. When combined with CEA, he diagnostic value improved. }{ }^{57} \\
\text { Other markers such as NEAT1, ZFAS1, and GAS5 showed promising results for potential use as a diagnostic or prognostic } \\
\text { marker. }\end{array}$ \\
\hline $\begin{array}{l}\text { Insulin-like growth } \\
\text { factor binding protein } \\
2 \text { (IGFBP-2) }\end{array}$ & $\begin{array}{l}\text { An elevated serum IGFBP-2 level is associated with malignancies of the colon, ovary, and prostate as well as other } \\
\text { advanced solid tumors. }{ }^{62-65} \text { Although the sensitivity and specificity of IGFBP-2 alone is unsatisfactory for early CRC and } \\
\text { colon polyp detection, the combination of IGFBP-2 and CEA could increase its sensitivity. }{ }^{61,66}\end{array}$ \\
\hline \multicolumn{2}{|l|}{ Stool biomarker } \\
\hline $\begin{array}{l}\text { Guaiac fecal occult blood } \\
\text { test (gFOBT) }\end{array}$ & $\begin{array}{l}\text { Use of the gFOBT as a CRC screening test reduced mortality by 11\%-33\% over } 20 \text { years of follow-up. }{ }^{67-69} \text { However, it } \\
\text { cannot distinguish upper Gl bleeding from lower Gl bleeding or human heme from non-human heme. }\end{array}$ \\
\hline $\begin{array}{l}\text { Fecal immunochemical } \\
\text { test (FIT) }\end{array}$ & $\begin{array}{l}\text { The FIT detects human globin using a human hemoglobin-specific immunoassay. }{ }^{72} \text { It has higher sensitivity and specificity } \\
\text { than gFOBT for detecting CRC and advanced adenomas. }\end{array}$ \\
\hline Stool DNA (sDNA) & $\begin{array}{l}\text { The Cologuard test (multi-target stood DNA test for CRC) showed higher sensitivity than gFOBT and FIT but also a higher } \\
\text { false positive rate. }\end{array}$ \\
\hline Stool miRNA & $\begin{array}{l}\text { miR-92a, miR-21, miR144, miR-106a, miR17-92 cluster, miR135 were up-regulated in CRC, while miR-143 and miR- } \\
145 \text { were down-regulated in CRC. }{ }^{92-94} \text { However, none of the miRNAs showed adequate predictive value for use as a } \\
\text { standalone CRC diagnostic test. }\end{array}$ \\
\hline
\end{tabular}

CRC, colorectal cancer; TBT, Telomerase Biosensor Technology; HIF1A-AS1, hypoxia-inducible factor 1alpha-antisense RNA 1; AUC, area under the curve; CRNDE-h, colorectal neoplasia differentially expressed-h. 


\section{DIAGNOSTIC BIOMARKERS (Table 1)}

\section{Tissue Biomarkers}

\section{1) Cytokeratins}

Cytokeratins (CKs) are keratin proteins found in the intracytoplasmic cytoskeleton of epithelial tissue. To differentiate metastatic CRC from other tumors, tissues can be stained for CK7 and CK20. CRC specimens usually stain positive for CK20 and negative for CK7. ${ }^{10} \mathrm{CK} 20$ is selectively present in the normal gland cells of the colonic mucosa and Merkel cells. In contrast, CK7 is not detected in the colonic mucosa. CK7 is expressed in bladder and female genital tract epithelia, mesothelium, and normal lung. ${ }^{11}$ CK staining patterns are among the most helpful procedures for identifying metastatic adenocarcinoma of unknown primary origin. Detecting the CK7-/CK20+ pattern is a typical method for metastatic CRC diagnosis. ${ }^{12} \mathrm{~A}$ reported $65 \%$ to $95 \%$ of CRC cases show a CK7-/CK20+ pattern. ${ }^{10}$

\section{2) Caudal type homeobox 2}

Caudal type homeobox 2 (CDX2) codes for a homeobox protein that is critically involved in the regulation of normal cell differentiation in the GI tract and tumor suppression in the colon. Werling et al. ${ }^{13}$ revealed that the loss of CDX2 expression might result in CRC. They also found that immunohistochemical detection of CDX2 protein expression could be used to identify CRC from other adenocarcinomas of the GI tract. According to the study findings, high CDX2 expression levels were found in CRC, while intermediate CDX2 expression levels were found in other adenocarcinomas of the GI tract. Other than CK pattern, assessing CDX2 expression is also a very sensitive and specific manner of identifying CRC. Many studies have evaluated CDX2 expression in CRC, and its sensitivity and specificity are reportedly greater than $90 \%{ }^{13,14}$ However, many studies found that CDX2 is also expressed in other adenocarcinomas of the GI tract such as adenocarcinoma of the stomach (33\%-70\%). CDX2 expression alone cannot differentiate among adenocarcinomas of the GI tract. ${ }^{13,14}$ Therefore, it is very useful when used as an adjunct to CK staining, especially in patients with a $\mathrm{CK} 7+/ \mathrm{CK} 20+$ or $\mathrm{CK} 7-/ \mathrm{CK} 20$ - profile.

\section{3) Special AT-rich sequence binding protein 2}

Special AT-rich sequence binding protein 2 (SATB2) is part of the matrix attachment region-binding transcription factors family. ${ }^{15}$ Although the exact role of SATB2 in the GI tract is unknown, Magnusson et al. ${ }^{16}$ found that SATB2 is highly expressed in the epithelium of the lower GI tract including the appendix, colon, and rectum. The authors checked the expression profile of SATB2 in 216 cancer samples and found that the majority of CRC samples, including that of poorly differentiated CRC, showed strong SATB2 expression. SATB2 used as a single marker showed positivity in $87.8 \%(943 / 1,074)$ of CRC cases. ${ }^{16,17}$ Other carcinomas from the ovary and lung rarely stained positive for SATB2 expression $(<7 \%) .{ }^{17}$ Many studies have evaluated the benefit of the addition of SATB2 to the standard panels of CK7, CK20, and CDX2. Dragomir et al. ${ }^{18}$ reported that the addition of SATB2 to standard panels showed no significant improvement in sensitivity or specificity in the diagnosis of CRC. In contrast, 2 recent studies reported that SATB2 could be a specific marker for differentiating metastatic CRC from primary ovarian carcinomas. Before the identification of SATB2, CDX2 was the most specific marker available. However, CDX2 tested positive in $18 \%$ of ovarian carcinomas, whereas SATB2 was expressed in 95\% of metastatic CRC and $0 \%$ of ovarian carcinomas. ${ }^{1920}$ Therefore, SATB2 could be used as a marker to exclude ovarian carcinomas.

\section{4) Cadherin 17}

Cadherins are cell-cell adhesion molecules that play important roles in maintaining tissue structure under normal conditions. ${ }^{21}$ Molecular defects in cadherin expression are associated with many human diseases, including carcinomas. ${ }^{22} \mathrm{Cad}-$ herin 17 (CDH17), a member of the cadherin superfamily, was first identified in the rat liver and intestine. ${ }^{23}$ Later on, 3 immunohistochemical studies consisting of a large number of human tissues found that $\mathrm{CDH} 17$ was expressed on the surface epithelium of the duodenum, ileum, appendix, and colon. ${ }^{24-26}$ Many recent studies have indicated that $\mathrm{CDH} 17$ could be a good immunohistochemical marker for the diagnosis of adenocarcinomas of the GI tract. CDH17 is reportedly expressed in $96 \%$ to $100 \%$ of primary and $100 \%$ of metastatic CRC. . $^{25-27}$ CDH17 is also expressed in other GI tumors such as gastric, pancreatic, and biliary cancer but it is rarely found outside the GI tract. ${ }^{28}$ Although CDH17 is transcriptionally regulated by CDX2, some studies indicated that $\mathrm{CDH} 17$ is more sensitive and specific than CDX2 for the identification of CRC. ${ }^{27,28}$

\section{5) Telomerase}

Telomerase is a ribonucleoprotein that maintains telomeres by adding TTAGGG repeats onto telomeres that are located at the ends of chromosomes. Telomerase uses intrinsic RNA as a template for reverse transcription. ${ }^{29}$ In normal cells, telomeres shorten with each cell division. When telomeres become criti- 
cally shortened, a signal of DNA damage is induced that results in replicative senescence. ${ }^{30}$ Cancer cells bypass DNA damage-induced inhibitory signaling pathways by upregulating telomerase. Telomerase is found in $85 \%$ to $90 \%$ of all malignant tumors. ${ }^{31}$ Using the novel assay Telomerase Biosensor Technology (TBT; Sienna Cancer Diagnostics, Melbourne, Australia), telomerase has become a new diagnostic biomarker in CRC. According to the study, it is predicted to show 95\% specificity and $95 \%$ sensitivity in melanoma, bladder cancer, and CRC. ${ }^{32}$

\section{6) GPA33}

The GPA33 (A33) gene codes for membranous protein A33, a membrane-bound glycoprotein with a homolog in the immunoglobulin superfamily. ${ }^{33}$ Although the function of A33 is not yet understood, it might be associated with immunological processes, proliferation, and colonic mucosal repair as reported by an animal study. ${ }^{34}$ Immunohistochemical studies have found that A33 is expressed by epithelial cells in the stomach, small intestine, colon, and rectum. It is expressed in more than 95\% of human CRC cases, especially in well-differentiated tumors, indicating that it could be a potential target for CRC treatment. ${ }^{35}$ An immunohistological study comparing A33 and CDX2 revealed that A33 showed sensitivity similar to that of CDX2 but specificity higher than that of CDX2 as an immunomarker of $\mathrm{CRC}^{36}$

\section{Blood Biomarkers}

\section{1) Chromosomal instability}

Chromosomal instability (CIN) is defined as gain or loss of whole or large portions of chromosomes leading to karyotypic variability, resulting in sub-chromosomal genomic amplifications, changes in chromosome numbers, and a high loss of heterozygosity ( $\mathrm{LOH}$ ) rate. CIN is the most common form of genetic instability observed in CRC $(65 \%-70 \%))^{37}$ Mutations in tumor suppressor genes (TSGs) and oncogenes such as APC, CTNNB1, KRAS, PIK3CA, and TP53, and LOH of chromosome $18 \mathrm{q}$ were the key events that lead to the development of CIN CRC. ${ }^{38-40}$

\section{2) Circulating cell-free DNA}

Circulating cell-free DNA (cfDNA) is a type of cell-free nucleic acid derived from normal and tumor cells that enters into the bloodstream by apoptosis or necrosis. ${ }^{41}$ The lengths of cfDNA strands differ among processes by which they are made. In healthy individuals, cfDNA is released from apoptotic cells, and the DNA fragments are about $180 \mathrm{bp}$ long. However, in tumor cells, cfDNA is released as much larger fragments by necrosis. ${ }^{41}$ Therefore, the quantitative analysis of circulating cfDNAs by measuring the ratio of longer and shorter DNA fragments, in other words, measuring cfDNA integrity number during the diagnosis of $\mathrm{CRC}$, showed some promising results. Hao et al. ${ }^{42}$ reported that cfDNA integrity number measured by qualitative PCR method showed a sensitivity of $73.08 \%$ and specificity of $97.27 \%$. Later, El-Gayar et al. ${ }^{43}$ reported that cfDNA integrity number measured by RT-PCR reaction showed sensitivity of $90 \%$ and specificity of $85 \%$. The concentrations of cfDNA differed between healthy and CRC patients. CRC patients showed a five times higher concentration of serum cfDNA and 25 to 50 times higher concentrations of plasma cfDNA than healthy controls. ${ }^{43-45}$ Wang et al. ${ }^{46}$ performed a systematic review and meta-analysis of circulating cfDNA as a diagnostic marker for CRC. Fourteen studies were analyzed which included 1,258 CRC patients and 803 healthy controls. Quantitative analysis of circulating cfDNA for the diagnosis of CRC showed $73.5 \%$ sensitivity and $91.8 \%$ specificity, suggesting that it had acceptable specificity for the diagnosis of CRC. The integrity index showed better diagnostic accuracy for CRC than did absolute DNA concentration.

\section{3) MicroRNA}

MicroRNAs (miRNAs) are 18-25 bp-long small noncoding RNAs that regulate gene expression by binding to mRNA. The miRNAs are reportedly associated with many cancers including CRC by acting as oncogenes or TSGs. ${ }^{47}$ Compared to mRNA, miRNAs show higher stability in the blood since they avoid degradation by endogenous RNase and are resistant to extreme $\mathrm{pH}$ changes. For these reasons, miRNA are promising noninvasive biomarkers in cancer. ${ }^{48}$ Studies have assessed their diagnostic ability for CRC in single or panels of miRNA.

Many studies reported that miR-21 could be a promising diagnostic marker for CRC. One study reported that miR-21 showed $90 \%$ specificity and sensitivity for CRC detection. ${ }^{49,50}$ Another study reported that the combination of miR-141 and CEA improved CRC detection accuracy. High levels of miR141 were associated with poor survival, indicating that it may be used as a prognostic marker. ${ }^{51}$

Other studies assessing different combinations of miRNAs showed better results. A panel of mi-24, mi-320a, and mi-423$5 \mathrm{q}$ showed $92.8 \%$ sensitivity and $70.8 \%$ specificity for detecting CRC. ${ }^{52}$ Another study reported that a panel of 6 serum miRNA (miR-21, let-7g, miR-31, miR-92a, miR-181b, and miR- 
203) showed $93 \%$ sensitivity and $91 \%$ specificity for detecting CRC, comparable to those of conventional tumor markers CEA and CA19-9. ${ }^{53}$

\section{4) Long noncoding RNAs}

Long noncoding RNAs (lncRNAs), which consist of more than 200 nucleotides that cannot translate to protein, are implicated in various biological processes such as epigenetic regulation, immune responses, differentiation, and chromosome dynamics. ${ }^{54}$ At this point, more than 150 human disease are reportedly associated with IncRNAs, such as colon cancer, breast cancer, leukemia, and psoriasis. ${ }^{55}$ Studies have assessed their diagnostic ability for CRC using single or panel lncRNAs.

Serum hypoxia-inducible factor (HIF) lalpha-antisense RNA 1 (HIF1A-AS1) was significantly elevated in 151 CRC patients versus that in 160 healthy controls and showed a high diagnostic ability for CRC with an area under the curve (AUC) of 0.960 (95\% CI, 0.940-0.980; $P<0.001$ ). CRC patients with high HIF1A-AS1 expression were associated with a shorter 5-year survival rate than those with low expression, indicating that HIF1A-AS1 could be used as a CRC diagnostic and prognostic biomarker. ${ }^{56}$

Colorectal neoplasia differentially expressed-h (CRNDE-h), a splice variant of CRNDE, was shown to distinguish CRC patients from healthy individuals. Serum CRNDE-h levels were significantly elevated in CRC patients compared to those in patients with benign disease or healthy controls. Compared to conventional tumor marker CEA, the diagnostic value of CRNDE-h was better that the AUC value for distinguishing CRC patients from healthy controls was 0.892 and 0.688 , respectively. AUC value improved to 0.913 when CRNDE-h levels were combined with CEA. Also, the elevated CRNDE-h level was significantly associated with lymph node involvement and distant metastases, and patients with an elevated CRNDE$\mathrm{h}$ level had poor overall survival (OS) rates. ${ }^{57}$

Other lncRNAs such as NEAT $1,{ }^{58}$ ZNFX1 antisense RNA1 (ZFAS1), ${ }^{59}$ and $\mathrm{GAS}^{60}{ }^{60}$ showed some promising results of their potential use as CRC diagnostic or prognostic biomarkers.

\section{5) Insulin-like growth factor binding protein 2}

Insulin-like growth factor binding protein 2 (IGFBP-2) is a binding protein that modulates the interaction between insulin-like growth factor (IGF) ligands and IGF-1 receptors. ${ }^{61}$ Although the physiological role of IGFBP-2 is not clearly understood, several studies have reported that serum IGFBP-2 level elevations are associated with malignancies of the colon, ovary, and prostate as well as other advanced solid tumors. ${ }^{62-65}$ Liou et al.$^{66}$ reported that elevated serum and plasma IGFBP-2 levels could distinguish patients with CRC or colon polyps from healthy controls. Although the sensitivity and specificity of IGFBP-2 alone is unsatisfactory for early CRC and colon polyp detection, its combination of IGFBP-2 with other biomarkers such as CEA could increase the sensitivity. Also, higher plasma IGFBP-2 levels were associated with larger tumor size and worse OS rates, indicating that IGFBP-2 might serve as a diagnostic and prognostic biomarker for CRC. ${ }^{61}$

\section{Stool Biomarkers}

\section{1) Fecal occult blood and immunochemical test}

The guaiac fecal occult blood test (gFOBT) and fecal immunochemical test (FIT) are widely used non-invasive techniques for screening for CRC. According to randomized control clinical trials, gFOBT as a CRC screening test reduced mortality by $11 \%-33 \%$ over 20 years of follow-up. ${ }^{67-69}$ However, its use as a biomarker has many limitations: It cannot distinguish bleeding between the upper and lower GI tract; cannot distinguish human heme from non-human heme; and is easily affected by drugs or diet. $^{70}$ Therefore, it shows only $30 \%$ to $40 \%$ sensitivity for detecting cancerous and precancerous lesions. ${ }^{71}$ These limitations of gFOBT have led to the development of FIT, which detects human globin using a human hemoglobin-specific immunoassay. It can detect both the presence and the quantity of fecal hemoglobin. Therefore, the cutoff level for this test can be selected, which might be advantageous. ${ }^{72}$ Compared to gFOBT, FIT has many advantages: it has higher sensitivity and specificity for $\mathrm{CRC}$ and advanced adenomas (AAs) $;^{73}$ it requires only 1 stool sample (vs. 3); it is more cost-effective; and it provides more quality-adjusted life years than gFOBT $^{74}{ }^{74}$ However, the FIT also has limitations. In detecting adenomas $>1 \mathrm{~cm}$ in diameter, FIT showed only $20 \%$ to $30 \%$ sensitivity. ${ }^{75}$ Moreover, the occult blood test can detect left-sided lesions in the colon much more than right-sided lesions. ${ }^{75,76}$ This is an important limitation since the incidence of right-sided CRC has been increasing over the past 2 decades. ${ }^{77}$ Therefore, neither gFOBT nor FIT can stand alone as a diagnostic tool.

\section{2) Other stool-based tests}

Stool-based assays are considered the most successful type for many reasons. According to direct histological observations, CRC and polyps exfoliate many neoplastic cells and their debris into the mucocellular layer of the colonic lumen. ${ }^{72}$ The detectable molecular changes that are caused by CRC cells are 
reportedly present in the stool earlier than in the blood. ${ }^{78}$ The actual unfolded surface area of the epithelial monolayer of cancers and polyps could be 200 times larger than that predicted by gross findings. ${ }^{79}$ However, despite abundant cellular exfoliation from large surface areas and neoplastic cells in the mucocellular areas, exfoliated colonocytes rarely survive if they are shed in the right colon due to intra-luminal lysis. ${ }^{80}$ Hence, after cell lysis, the detection of components of the exfoliated cells, such as DNA, miRNA, and proteins, could be useful.

\section{3) Stool DNA}

Less than $0.01 \%$ of the total DNA in the stool is human DNA, while the other $99.99 \%$ is derived from intestinal bacteria or the diet. Therefore, detecting methylated or mutated human DNA in the stool is an important technique for diagnosing $\mathrm{CRC}^{81}$ Several panels of methylated genes within stool DNA (sDNA), such as $A P C, A T M, B M P 3, C D H 1, C D K N 2 A, C D H 13$, CRBP1, CXCL21, ESR1, GATA4, GSTP1, HLTF, ID4, IRF8, ITGA4, KRAS, MINT1, MINT31, MLH1, MGMT, NDRG4, RASSF2A, SFRP2, TFPI2, VIM, and WIF1, have been analyzed for the diagnosis of CRC. ${ }^{82-85}$ To date, the United States Food and Drug Administration has approved only the Cologuard test (multitarget stool DNA test for CRC) for CRC screening. Compared to the gFOBT, the Cologuard test shows better sensitivity (13\% vs. $52 \%$ ) for detecting CRC. However, no improvement was seen in detecting large ( $>1 \mathrm{~cm}$ ) adenomas ( $10.3 \% \mathrm{vs} .10 .7 \%)^{86}$ Similar results were observed when the sDNA test was compared to the FIT: the former showed higher sensitivity but a higher false positive rate as well. ${ }^{87}$ To improve the early detection rate of CRC and AAs, some studies have combined the sDNA test and FIT. The majority of studies reported that the sensitivity for detecting CRC and AAs was higher with the sDNA test plus the FIT compared to the FIT alone. However, since the false positivity rate was higher, the demand for colonoscopy was more than twice that of the sDNA test plus FIT compared to the FIT alone. Also, the specificity for detecting CRC was lower for the sDNA test plus the FIT compared to the FIT alone. ${ }^{88-90}$

\section{4) Stool miRNA}

Since the environment of the GI tract is much more complicated than that of the blood, marker stability within it is a major concern. Many studies have shown that, unlike rapid degradation of mRNA and protein, miRNA transcripts were more stable in various conditions. ${ }^{47,91}$ Although there are limited data about miRNA in the stool compared to that in the blood, dysregulation of miRNA expression was found in the stool of CRC patients; miR-92a, miR-21, miR144, miR-106a, miR17-92 cluster, and miR135 were up-regulated in CRC; and miR-143 and miR-145 were down-regulated in CRC. ${ }^{92-94}$ However, none of the miRNAs showed adequate predictive value for use as a CRC diagnostic test alone, and future studies are needed to improve the diagnostic value of miRNA by combining several miRNAs. ${ }^{92}$

\section{PROGNOSTIC BIOMARKERS (Table 2)}

\section{Tissue Biomarkers \\ 1) BRAF}

The mitogen-activated protein kinase pathway, which consists of RAS-RAF-MEK-ERK, is associated with cell differentiation, migration, angiogenesis, and proliferation. The dysregulation of this pathway leads to carcinogenesis. ${ }^{95}$ Approximately $8 \%$ of advanced CRC and $14 \%$ of localized stage II and III CRC cases have $B R A F$-activating mutations. ${ }^{96,97}$ According to the metaanalysis of $\mathrm{Li}$ and $\mathrm{Li}^{98}$ the BRAF mutation was significantly associated with a tumor location in the proximal colon, poor differentiation, tumor size, and female sex. Advanced CRC patients with the BRAF mutation showed poorer progressionfree survival (PFS) and OS rates and lower response rates to anti-epidermal growth factor receptor (EGFR) therapy than those without $B R A F$ mutations. Patients with localized stage II and III CRC with BRAF mutations also showed poorer OS rates ${ }^{99,100}$ Supported by these results, in 2017, the American Society of Clinical Oncology (ASCO) published the guideline for the use of molecular biomarkers for CRC. BRAF p.V600 accounts for more than $90 \%$ of $B R A F$ mutations, and is recommended to be analyzed for its prognostic value. ${ }^{101}$

\section{2) Microsatellite instability}

Microsatellites are repeating DNA sequences of 1-6 bp that can be found in coding and noncoding regions. The mismatch repair (MMR) system fixes DNA errors that occur during replication. Microsatellite instability (MSI) results from inactivation of the MMR genes through sporadic MLH1 promoter hypermethylation ( $80 \%$ of MSI CRC cases) or germline mutations in MMR genes such as MLH1, MSH2, MSH6, or PMS2 (20\% of MSI CRC cases). ${ }^{102,103}$ The presence of deficient MMR leads to the accumulation of somatic mutations and induces genomic instability, causing cancer-associated alterations. ${ }^{104}$ Lynch syndrome, also called hereditary non-polyposis colon cancer, is caused by germline mutations in MMR genes that 
Table 2. Summary of Prognostic Biomarkers

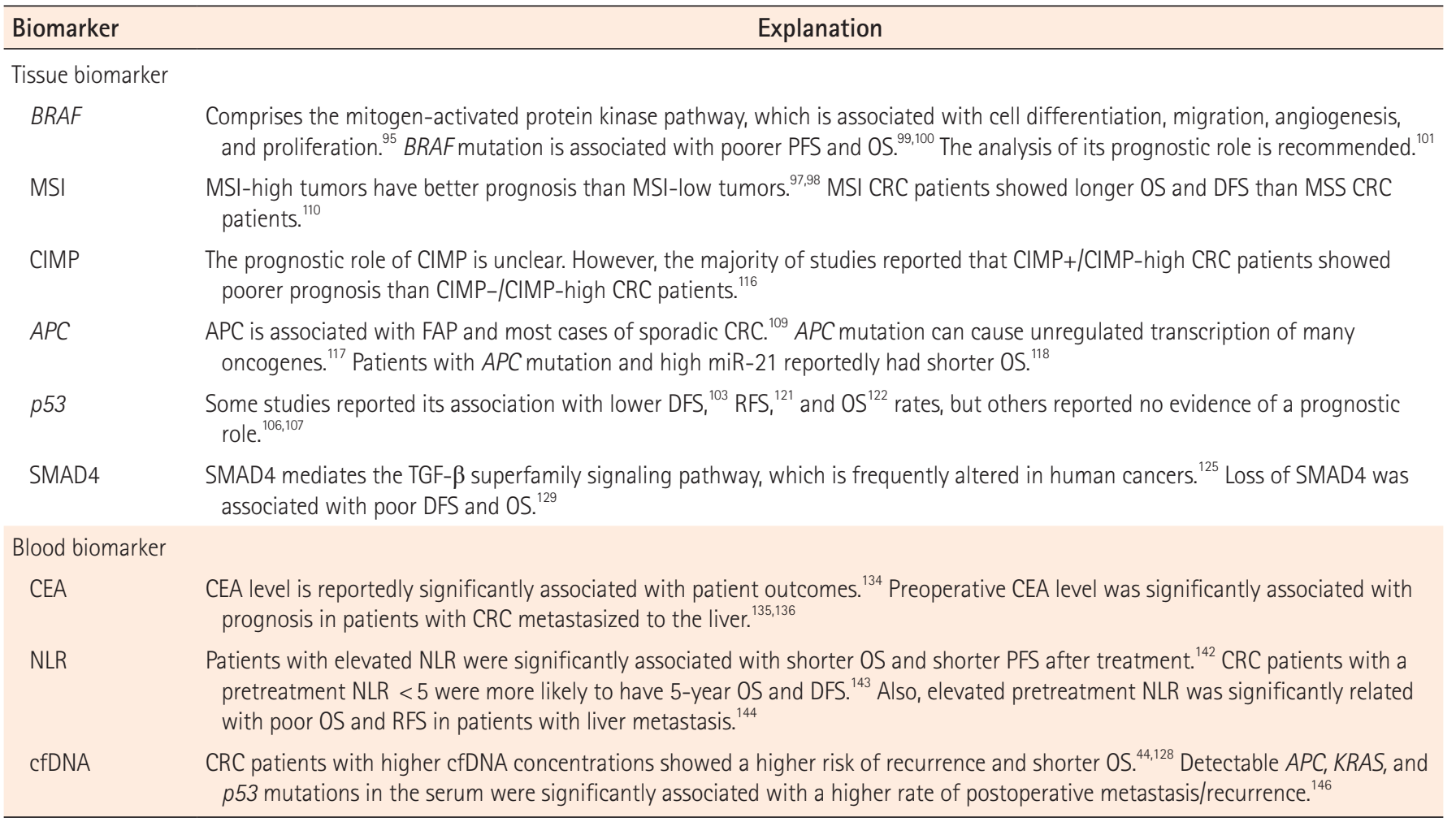

PFS, progression-free survival; OS, overall survival; MSI, microsatellite instability; CRC, colorectal cancer; DFS, disease-free survival; MSS, microsatellite stable; CIMP, cytosine preceding guanine island methylator phenotype; FAP, familial adenomatous polyposis; RFS, relapse-free survival; TGF- $\beta$, transforming growth factor- $\beta$; NLR, neutrophil-to-lymphocyte ratio.

lead to MSI. ${ }^{105}$ MSI is also associated with sporadic CRC. In sporadic MSI CRC, hypermethylation of the MLH1 promoter region causes MLH1 silencing. ${ }^{106}$ MMR status testing is recommended for patients with CRC for prognostic stratification. ${ }^{107}$ There are 5 commonly used microsatellite markers, including 2 mononucleotide repeats (BAT26 and BAT25) and 3 dinucleotide repeats (D2S123, D5S346, and D17S250). If a marker shows greater than $30 \%-40 \%$ instability, it is identified as MSIhigh. ${ }^{108}$ MSI-high tumors are more likely to be poorly differentiated, contain mucin, and possess subepithelial lymphoid aggregates and intraepithelial lymphocytes. Although the cause is unknown, MSI-high tumors have better prognosis than MSIlow tumors, possibly due to these immune responses. ${ }^{108,109}$ Guastadisegni et al. ${ }^{110}$ reviewed 13 studies to evaluate the prognostic value of MSI in CRC patients and reported that MSI CRC patients showed longer OS and disease-free survival (DFS) than microsatellite stable CRC patients.

\section{3) Cytosine preceding guanine island methylator phenotype}

Cytosine preceding guanine $(\mathrm{CpG})$ islands are regions that are common in promoter sites rich in $\mathrm{CpG}$ dinucleotides. $\mathrm{Ab}$ - normal DNA methylation has been observed in almost all CRCs. CpG island methylator phenotype (CIMP) CRC (10\%-20\%) have extremely high proportions of aberrantly methylated $\mathrm{CpG}$ loci. ${ }^{111}$ Hypermethylation in CpG islands silences genetic activity and result in dysregulated gene expression. ${ }^{112}$ CIMP is often defined as hypermethylation of at least 3 loci in a selected panel of 5 genes ( $h M L H 1$, p16, MINT1, MINT3, and MINT31) that are associated with $\mathrm{CpG}$ islands. ${ }^{113}$ Since CIMP was a recently identified phenotype, methylated loci that are used to define CIMP have not yet been established. ${ }^{114,115}$ This might be the reason why the prognostic role of CIMP remains unclear. However, the majority of studies reported that CIMP+/CIMPhigh CRC patients showed poorer prognosis than CIMP-/CIMPhigh CRC patients. ${ }^{116}$

\section{4) $A P C$}

$A P C$ gene mutation is associated with familial adenomatous polyposis and most sporadic CRC cases. ${ }^{109} \mathrm{APC}$ has an important role in Wnt signaling, which is associated with cytoskeletal integrity, cellular proliferation, motility, and apoptosis by $\beta$-catenin regulation. APC mutation can increase $\beta$-catenin 
levels, leading to increased c-myc expression, which is associated with cell proliferation. Therefore, $A P C$ mutation can cause the unregulated transcription of many oncogenes. ${ }^{117}$ It was recently reported that in advanced-stage CRC, patients with $A P C$ mutation and high miR-21 had shorter OS, indicating that $A P C$ mutation could be a measure to predict the clinical outcomes of CRC. ${ }^{118}$

\section{5) $p 53$}

CRC (50\%-70\%) have mutations in the TSG $p 53 .{ }^{119}$ When DNA is damaged, $p 53$ causes cell cycle arrest to repair the mutations; if the mutations cannot be repaired, apoptosis is induced. ${ }^{109}$ Many studies have examined p53 mutations and their prognostic value in CRC patients. However, the results are contradictory. Some studies reported that $p 53$ mutation/overexpression is associated with lower DFS, ${ }^{120}$ relapse-free survival (RFS), ${ }^{121}$ and $\mathrm{OS}^{122}$ rates. Other studies reported that there is no evidence that $p 53$ status has prognostic value. ${ }^{123,124}$

\section{6) SMAD4}

Mutations in the TSG SMAD4, located on chromosome 18q21, leads to the loss of SMAD4 protein expression. SMAD4 mediates the transforming growth factor- $\beta$ superfamily signaling pathway, which is frequently altered in human cancers. ${ }^{125}$ It is associated with cell proliferation, differentiation, apoptosis, and cell migration. ${ }^{126}$ A reported $30 \%$ to $40 \%$ of CRC cases show SMAD4 mutations. ${ }^{127,128}$ Voorneveld et al. ${ }^{129}$ performed a meta-analysis to clarify the prognostic value of SMAD4 in CRC patients. According to the study findings, loss of SMAD4 was associated with poor DFS and OS.

\section{Blood Biomarkers}

\section{1) CEA levels}

CEA is the only marker that has been recommended by the ASCO 2006 update of recommendations for the management of CRC patients. CEA testing every 3 months post-surgery is recommended for patients with stage II or III CRC ${ }^{130}$ Renehan et al. ${ }^{131}$ reviewed 5 trials of patient follow-up after curative resection of CRC. The authors reported that intensive follow-up consisting of CEA testing every 3-6 months and CT every 3-12 months significantly reduced mortality. According to another meta-analysis done by Rosen et al., ${ }^{132}$ the intensive follow-up group showed a higher cumulative 5 -year survival rate than the control group ( $72.1 \%$ vs. $63.7 \%$ ).

Many studies have supported the prognostic value of preoperative CEA levels. ${ }^{133}$ Park et al. ${ }^{134}$ analyzed 2,230 CRC patients and found that CEA level was significantly associated with patient outcomes. According to 2 large-scale case studies, preoperative CEA level was significantly associated with prognosis in patients with CRC that metastasized to the liver. ${ }^{135,136}$

\section{2) Neutrophil-to-lymphocyte ratio}

Lymphopenia is associated with impaired cell-mediated immunity, while neutrophilia is associated with systemic inflammation. ${ }^{137}$ The neutrophil-to-lymphocyte ratio (NLR) was first studied as a marker for immune responses to various stressful conditions. ${ }^{138}$ Other studies found potential for NLR as a prognostic marker for pancreatic cancer, ${ }^{139}$ gastric cancer, ${ }^{140}$ and hepatocellular carcinoma. ${ }^{141}$ However, few systemic reviews and meta-analyses have examined the prognostic role of NLR in CRC. Li et al. ${ }^{142}$ reported that patients with elevated NLR was significantly associated with shorter OS and PFS after treatment. Also, elevated NLR was significantly associated with elevated CEA level. Tsai et al. ${ }^{143}$ reported similar results after analyzing 15 studies including 7,741 CRC patients. CRC patients with a NLR $<5$ before treatment were more likely to have 5-year OS and DFS. Tang et al. ${ }^{144}$ reviewed and analyzed a total of 1,685 CRC patients from 8 studies and reported that elevated pretreatment NLR was significantly related to poor OS and RFS in patients with liver metastasis.

\section{3) Concentration of cfDNA}

A higher cfDNA concentration is reportedly related to significantly shorter OS in CRC patients. Furthermore, CRC patients with higher cfDNA levels showed a higher risk of recurrence and shorter OS. ${ }^{44,145}$ Similarly, Wang et al. ${ }^{146}$ observed $A P C, K R$ $A S$, and $p 53$ mutations in the serum and found that patients with detectable cfDNA showed significantly higher rates of postoperative metastasis/recurrence than those without detectable cfDNA. Another study reported that patients with the KRAS mutation in the plasma and tissue showed shorter OS, indicating that the KRAS mutation in the plasma could be a prognostic marker for a poor outcome. ${ }^{147}$

\section{PREDICTIVE BIOMARKERS (Table 3)}

\section{Tissue Biomarkers \\ 1) KRAS and NRAS}

It has been reported that more than $50 \%$ of CRC cases show KRAS, NRAS, and BRAF mutations. ${ }^{148}$ The KRAS proto-oncogene encodes a GTPase protein (KRAS) that plays an essential role in many molecular pathways, including the EGFR path- 
Table 3. Summary of Predictive Biomarkers

\begin{tabular}{|c|c|}
\hline Biomarker & Explanation \\
\hline \multicolumn{2}{|c|}{ Tissue biomarker } \\
\hline KRAS, NRAS & $\begin{array}{l}\text { KRAS proto-oncogene encodes a GTPase protein (KRAS) that plays an essential role in many molecular pathways including } \\
\text { the EGFR pathway. }{ }^{149} \text { Only wild-type RAS tumors showed the clinical benefit of anti-EGFR antibody therapy. KRAS mutations } \\
\text { can be used as a negative predictive factor of a response to EGFR inhibitors. }{ }^{150-153}\end{array}$ \\
\hline$B R A F$ & $\begin{array}{l}\text { It has been reported that there is insufficient evidence that BRAF mutation could be used as a predictive marker for the } \\
\text { benefit of anti-EGFR antibody therapy. }{ }^{155}\end{array}$ \\
\hline \multicolumn{2}{|c|}{ Blood biomarker } \\
\hline cfDNA & $\begin{array}{l}\text { The cfDNA concentration decreased after primary resection, but when the CRC relapsed, cfDNA levels dramatically } \\
\text { increased. }{ }^{45,145} \text { Similar results were found in rectal cancer patients who underwent chemoradiotherapy: The cfDNA } \\
\text { concentration decreased in responders but increased in nonresponders. }{ }^{165}\end{array}$ \\
\hline
\end{tabular}

EGFR, epidermal growth factor receptor; PFS, progression-free survival; OS, overall survival; CRC, colorectal cancer; cfDNA, cell-free DNA.

way. ${ }^{149}$ Only wild-type RAS tumors reportedly showed the clinical benefit of anti-EGFR antibody therapy such as cetuximab and panitumumab. As confirmed by both retrospective and prospective trials, KRAS mutations can be used as a negative predictive factor of a response to EGFR inhibitors. ${ }^{150-153}$ In 2017, ASCO reviewed 74,546 patients in 311 primary studies that compared treatment outcomes of patients with activated RAS mutation to those of the non-mutated type and recommended RAS mutational testing in all patients being considered for anti-EGFR therapy. ${ }^{154}$

\section{2) BRAF}

A meta-analysis performed by Rowland et al. ${ }^{155}$ to evaluate the effect of $B R A F$ mutation on anti-EGFR antibody therapy revealed that there was insufficient evidence that $B R A F$ could be used as a predictive marker for anti-EGFR antibody therapy success. Although the hazard ratio for OS and PFS with anti-EGFR antibody therapy was higher in RAS wild-type/BRAFmutated tumors than in RAS wild-type/BRAF wild-type tumors (OS: 0.97; 95\% CI, $0.67-1.41$ vs. 0.81; 95\% CI, 0.70-0.95 and PFS: 0.89 ; $95 \% \mathrm{CI}, 0.61-1.21$ vs. 0.62 ; $95 \% \mathrm{CI}, 0.50-0.77$, respectively); the results were not statistically significant $(P=0.43$ and $P=0.07$, respectively).

\section{3) PIK3CA}

PIK3CA encodes the p1 $10 \alpha$ catalytic subunit of the class IA phosphatidylinositol 3-kinases (PI3Ks), which play a major role in the RAS-mediated pathway that leads to proliferation, transformation, and tumor progression. ${ }^{156}$ PIK3CA mutation occurs $10 \%$ to $18 \%$ of CRC patients, primarily in exons 9 and $20 .{ }^{150}$
Many studies have reported that PIK3CA mutation might help predict a lack of benefit from anti-EGFR therapy in colon cancer, but the results were inconclusive. ${ }^{157,158}$ Huang et al. ${ }^{159}$ conducted a meta-analysis of 11 studies with 864 KRAS-wildtype metastatic CRC patients treated with anti-EGFR monoclonal antibodies. According to the study findings, patients with PIK3CA mutation showed a reduced response rate and poor PFS and OS in KRAS wild-type metastatic CRC patients. In particular, the PIK3CA mutation in exon 20 was significantly associated with a lack of response. On the other hand, Karapetis et al. ${ }^{160}$ reported that PIK3CA mutation status cannot be used as a predictive marker for a benefit from anti-EGFR monoclonal antibodies. Their results showed that PIK3CA mutation was not associated with lower OS or PFS from cetuximab therapy in KRAS wild-type CRC patients. Many studies have reported the protective effect of aspirin in CRC. ${ }^{161,162}$ A recent study reported that PIK3CA mutation could be a predictive marker for adjuvant aspirin therapy in CRC patients. Liao et al. ${ }^{163}$ studied 964 patients with CRC and found out that PIK3CA-mutated CRC patients showed longer cancer-specific survival and OS rates compared to PIK3CA wild-type CRC patients.

\section{Blood Biomarkers 1) Cell-free DNA}

Studies have found that the cfDNA concentration decreased after primary resection, but upon CRC relapse, cfDNA levels dramatically increased. ${ }^{45,145}$ Another study found that when circulating tumor DNA was detected after CRC surgery, it generally relapsed within 1 year. ${ }^{164}$ These results indicate that postoperative cfDNA measurement could predict and help detect 
recurrence earlier. Zitt et al. ${ }^{165}$ evaluated the cfDNA concentration before and after chemoradiotherapy for rectal cancer. The authors found that cfDNA concentration decreased in responders, whereas it increased in non-responders. Agostini et al. ${ }^{166}$ reported that post-chemoradiotherapy levels of the cfDNA integrity index was significantly lower in rectal cancer patients who responded to the therapy. Similar results were observed in other cancer studies. Patients who responded to the therapy showed decreased cfDNA, whereas those who did not respond to the therapy showed no change or increase in cfDNA. ${ }^{167}$

\section{CONCLUSIONS}

CRC is a common malignancy that contributes significantly to cancer mortality rates. Survival outcomes of CRC vary between patients because of the complexity of colorectal carcinogenesis. Therefore, it would be beneficial to identify reliable and practical molecular biomarkers that help in the diagnostic and therapeutic process of CRC. Recent research has been targeted to identify sensitive and specific biomarkers for the diagnosis and treatment outcomes of CRC. Here we provided an overview of the newer diagnostic, prognostic, and predictive biomarkers of CRC. Future studies are required to develop accurate diagnostic, prognostic, and predictive CRC biomarkers that could be more clinically applicable and offer greater patient acceptability than conventional biomarkers.

\section{FINANCIAL SUPPORT}

The authors received no financial support for the research, authorship, and/or publication of this article.

\section{CONFLICT OF INTEREST}

No potential conflict of interest relevant to this article was reported.

\section{AUTHOR CONTRIBUTION}

Conceptualization, writing, editing: Joo YE. Conceptualization and writing: Oh HH. Approval of final manuscript: all authors.

\section{ORCID}

\section{$\mathrm{OhHH}$}

Joo YE

https://orcid.org/0000-0002-3323-495X

https://orcid.org/0000-0003-0422-2439

\section{REFERENCES}

1. Brenner H, Kloor M, Pox CP. Colorectal cancer. Lancet 2014; 383:1490-1502.

2. Jass JR. Classification of colorectal cancer based on correlation of clinical, morphological and molecular features. Histopathology 2007;50:113-130.

3. Choi Y, Sateia HF, Peairs KS, Stewart RW. Screening for colorectal cancer. Semin Oncol 2017;44:34-44.

4. Latini G, De Felice C, Barducci A, et al. Clinical biomarkers for cancer recognition and prevention: a novel approach with optical measurements. Cancer Biomark 2018;22:179-198.

5. Hong SN. Genetic and epigenetic alterations of colorectal cancer. Intest Res 2018;16:327-337.

6. Ahmed FE. Development of novel diagnostic and prognostic molecular markers for sporadic colon cancer. Expert Rev Mol Diagn 2005;5:337-352.

7. Chand M, Keller DS, Mirnezami R, et al. Novel biomarkers for patient stratification in colorectal cancer: a review of definitions, emerging concepts, and data. World J Gastrointest Oncol 2018;10:145-158.

8. Pellino G, Gallo G, Pallante P, et al. Noninvasive biomarkers of colorectal cancer: role in diagnosis and personalised treatment perspectives. Gastroenterol Res Pract 2018;2018:2397863.

9. Nikolouzakis TK, Vassilopoulou L, Fragkiadaki P, et al. Improving diagnosis, prognosis and prediction by using biomarkers in CRC patients (review). Oncol Rep 2018;39:2455-2472.

10. Bayrak R, Yenidünya S, Haltas H. Cytokeratin 7 and cytokeratin 20 expression in colorectal adenocarcinomas. Pathol Res Pract 2011;207:156-160.

11. Stenling R, Lindberg J, Rutegård J, Palmqvist R. Altered expression of CK7 and CK20 in preneoplastic and neoplastic lesions in ulcerative colitis. APMIS 2007;115:1219-1226.

12. Bayrak R, Haltas H, Yenidunya S. The value of CDX2 and cytokeratins 7 and 20 expression in differentiating colorectal adenocarcinomas from extraintestinal gastrointestinal adenocarcinomas: cytokeratin 7-/20+ phenotype is more specific than CDX2 antibody. Diagn Pathol 2012;7:9.

13. Werling RW, Yaziji H, Bacchi CE, Gown AM. CDX2, a highly sensitive and specific marker of adenocarcinomas of intestinal origin: an immunohistochemical survey of 476 primary and metastatic carcinomas. Am J Surg Pathol 2003;27:303310.

14. Moskaluk CA, Zhang H, Powell SM, Cerilli LA, Hampton GM, Frierson HF Jr. Cdx2 protein expression in normal and malignant human tissues: an immunohistochemical survey us- 
ing tissue microarrays. Mod Pathol 2003;16:913-919.

15. Dobreva G, Dambacher J, Grosschedl R. SUMO modification of a novel MAR-binding protein, SATB2, modulates immunoglobulin mu gene expression. Genes Dev 2003;17:30483061 .

16. Magnusson K, de Wit M, Brennan DJ, et al. SATB2 in combination with cytokeratin 20 identifies over $95 \%$ of all colorectal carcinomas. Am J Surg Pathol 201 1;35:937-948.

17. Zhang YJ, Chen JW, He XS, et al. SATB2 is a promising biomarker for identifying a colorectal origin for liver metastatic adenocarcinomas. EBioMedicine 2018;28:62-69.

18. Dragomir A, de Wit M, Johansson C, Uhlen M, Pontén F. The role of SATB2 as a diagnostic marker for tumors of colorectal origin: results of a pathology-based clinical prospective study. Am J Clin Pathol 2014;141:630-638.

19. Moh M, Krings G, Ates D, Aysal A, Kim GE, Rabban JT. SATB2 expression distinguishes ovarian metastases of colorectal and appendiceal origin from primary ovarian tumors of mucinous or endometrioid type. Am J Surg Pathol 2016;40:419432.

20. Perez Montiel D, Arispe Angulo K, Cantú-de León D, Bornstein Quevedo L, Chanona Vilchis J, Herrera Montalvo L. The value of SATB2 in the differential diagnosis of intestinal-type mucinous tumors of the ovary: primary vs metastatic. Ann Diagn Pathol 2015;19:249-252.

21. Gumbiner BM. Cell adhesion: the molecular basis of tissue architecture and morphogenesis. Cell 1996;84:345-357.

22. Makrilia N, Kollias A, Manolopoulos L, Syrigos K. Cell adhesion molecules: role and clinical significance in cancer. Cancer Invest 2009;27:1023-1037.

23. Dantzig AH, Hoskins JA, Tabas LB, et al. Association of intestinal peptide transport with a protein related to the cadherin superfamily. Science 1994;264:430-433.

24. Takamura M, Sakamoto M, Ino Y, et al. Expression of liverintestine cadherin and its possible interaction with galectin-3 in ductal adenocarcinoma of the pancreas. Cancer Sci 2003; 94:425-430.

25. Su MC, Yuan RH, Lin CY, Jeng YM. Cadherin-17 is a useful diagnostic marker for adenocarcinomas of the digestive system. Mod Pathol 2008;21:1379-1386.

26. Lin F, Shi J, Zhu S, et al. Cadherin-17 and SATB2 are sensitive and specific immunomarkers for medullary carcinoma of the large intestine. Arch Pathol Lab Med 2014;138:1015-1026.

27. Panarelli NC, Yantiss RK, Yeh MM, Liu Y, Chen YT. Tissuespecific cadherin CDH17 is a useful marker of gastrointestinal adenocarcinomas with higher sensitivity than CDX2. Am
J Clin Pathol 2012;138:211-222.

28. Bian T, Zhao J, Feng J, et al. Combination of cadherin-17 and SATB homeobox 2 serves as potential optimal makers for the differential diagnosis of pulmonary enteric adenocarcinoma and metastatic colorectal adenocarcinoma. Oncotarget 2017;8:63442-63452.

29. Shay JW, Zou Y, Hiyama E, Wright WE. Telomerase and cancer. Hum Mol Genet 2001;10:677-685.

30. Campisi J. The biology of replicative senescence. Eur J Cancer 1997;33:703-709.

31. Shay JW, Bacchetti S. A survey of telomerase activity in human cancer. Eur J Cancer 1997;33:787-791.

32. Roig AI, Wright WE, Shay JW. Is telomerase a novel target for metastatic colon cancer? Curr Colorectal Cancer Rep 2009; $5: 203$.

33. Heath JK, White SJ, Johnstone CN, et al. The human A33 antigen is a transmembrane glycoprotein and a novel member of the immunoglobulin superfamily. Proc Natl Acad Sci U S A 1997;94:469-474.

34. Pereira-Fantini PM, Judd LM, Kalantzis A, et al. A33 antigendeficient mice have defective colonic mucosal repair. Inflamm Bowel Dis 2010;16:604-612.

35. Garinchesa P, Sakamoto J, Welt S, Real F, Rettig W, Old L. Organ-specific expression of the colon cancer antigen A33, a cell surface target for antibody-based therapy. Int J Oncol 1996;9:465-471.

36. Wong NACS, Adamczyk LA, Evans S, Cullen J, Oniscu A, Oien KA. A33 shows similar sensitivity to but is more specific than CDX2 as an immunomarker of colorectal carcinoma. Histopathology 2017;71:34-41.

37. Lengauer C, Kinzler KW, Vogelstein B. Genetic instabilities in human cancers. Nature 1998;396:643-649.

38. Pino MS, Chung DC. The chromosomal instability pathway in colon cancer. Gastroenterology 2010;138:2059-2072.

39. Smith G, Carey FA, Beattie J, et al. Mutations in APC, Kirstenras, and p53: alternative genetic pathways to colorectal cancer. Proc Natl Acad Sci U S A 2002;99:9433-9438.

40. Leslie A, Carey FA, Pratt NR, Steele RJ. The colorectal adenoma-carcinoma sequence. Br J Surg 2002;89:845-860.

41. Jahr S, Hentze H, Englisch S, et al. DNA fragments in the blood plasma of cancer patients: quantitations and evidence for their origin from apoptotic and necrotic cells. Cancer Res 2001;61:1659-1665.

42. Hao TB, Shi W, Shen XJ, et al. Circulating cell-free DNA in serum as a biomarker for diagnosis and prognostic prediction of colorectal cancer. Br J Cancer 2014;111:1482-1489. 
43. El-Gayar D, El-Abd N, Hassan N, Ali R. Increased free circulating DNA integrity index as a serum biomarker in patients with colorectal carcinoma. Asian Pac J Cancer Prev 2016;17: 939-944.

44. Frattini M, Gallino G, Signoroni S, et al. Quantitative analysis of plasma DNA in colorectal cancer patients: a novel prognostic tool. Ann N Y Acad Sci 2006;1075:185-190.

45. Spindler KL, Pallisgaard N, Andersen RF, Brandslund I, Jakobsen A. Circulating free DNA as biomarker and source for mutation detection in metastatic colorectal cancer. PLoS One 2015;10:e0108247.

46. Wang X, Shi XQ, Zeng PW, Mo FM, Chen ZH. Circulating cell free DNA as the diagnostic marker for colorectal cancer: a systematic review and meta-analysis. Oncotarget 2018;9: 24514-24524

47. Mitchell PS, Parkin RK, Kroh EM, et al. Circulating microRNAs as stable blood-based markers for cancer detection. Proc Natl Acad Sci U S A 2008;105:10513-10518.

48. Berger F, Reiser MF. Micro-RNAs as potential new molecular biomarkers in oncology: have they reached relevance for the clinical imaging sciences? Theranostics 2013;3:943-952.

49. Kanaan Z, Rai SN, Eichenberger MR, et al. Plasma miR-21: a potential diagnostic marker of colorectal cancer. Ann Surg 2012;256:544-551.

50. Ahmed FE, Amed NC, Vos PW, et al. Diagnostic microRNA markers to screen for sporadic human colon cancer in blood. Cancer Genomics Proteomics 2012;9:179-192.

51. Cheng H, Zhang L, Cogdell DE, et al. Circulating plasma MiR141 is a novel biomarker for metastatic colon cancer and predicts poor prognosis. PLoS One 2011;6:e17745.

52. Fang Z, Tang J, Bai Y, et al. Plasma levels of microRNA-24, microRNA-320a, and microRNA-423-5p are potential biomarkers for colorectal carcinoma. J Exp Clin Cancer Res 2015;34:86.

53. Wang J, Huang SK, Zhao M, et al. Identification of a circulating microRNA signature for colorectal cancer detection. PLoS One 2014;9:e87451.

54. Liu MX, Chen X, Chen G, Cui QH, Yan GY. A computational framework to infer human disease-associated long noncoding RNAs. PLoS One 2014;9:e84408.

55. Chen G, Wang Z, Wang D, et al. LncRNADisease: a database for long-non-coding RNA-associated diseases. Nucleic Acids Res 2013;41:D983-D986.

56. Gong W, Tian M, Qiu H, Yang Z. Elevated serum level of lncRNA-HIF1A-AS1 as a novel diagnostic predictor for worse prognosis in colorectal carcinoma. Cancer Biomark 2017;
20:417-424.

57. Liu T, Zhang X, Gao S, et al. Exosomal long noncoding RNA CRNDE-h as a novel serum-based biomarker for diagnosis and prognosis of colorectal cancer. Oncotarget 2016;7:8555185563.

58. Peng W, Wang Z, Fan H. LncRNA NEAT1 impacts cell proliferation and apoptosis of colorectal cancer via regulation of Akt signaling. Pathol Oncol Res 2017;23:651-656.

59. Fang C, Zan J, Yue B, Liu C, He C, Yan D. Long non-coding ribonucleic acid zinc finger antisense 1 promotes the progression of colonic cancer by modulating ZEB1 expression. J Gastroenterol Hepatol 2017;32:1204-1211.

60. Liu L, Meng T, Yang XH, et al. Prognostic and predictive value of long non-coding RNA GAS5 and mircoRNA-221 in colorectal cancer and their effects on colorectal cancer cell proliferation, migration and invasion. Cancer Biomark 2018;22: 283-299.

61. Renehan AG, Jones J, Potten CS, Shalet SM, O’Dwyer ST. Elevated serum insulin-like growth factor (IGF)-II and IGF binding protein-2 in patients with colorectal cancer. Br J Cancer 2000;83:1344-1350.

62. el Atiq F, Garrouste F, Remacle-Bonnet M, Sastre B, Pommier G. Alterations in serum levels of insulin-like growth factors and insulin-like growth-factor-binding proteins in patients with colorectal cancer. Int J Cancer 1994;57:491-497.

63. Baron-Hay S, Boyle F, Ferrier A, Scott C. Elevated serum insulin-like growth factor binding protein-2 as a prognostic marker in patients with ovarian cancer. Clin Cancer Res 2004; 10:1796-1806.

64. Kanety H, Madjar Y, Dagan Y, et al. Serum insulin-like growth factor-binding protein-2 (IGFBP-2) is increased and IGFBP-3 is decreased in patients with prostate cancer: correlation with serum prostate-specific antigen. J Clin Endocrinol Metab 1993;77:229-233.

65. Eiseman JL, Guo J, Ramanathan RK, et al. Evaluation of plasma insulin-like growth factor binding protein 2 and Her-2 extracellular domain as biomarkers for 17-allylamino-17demethoxygeldanamycin treatment of adult patients with advanced solid tumors. Clin Cancer Res 2007;13:2121-2127.

66. Liou JM, Shun CT, Liang JT, et al. Plasma insulin-like growth factor-binding protein-2 levels as diagnostic and prognostic biomarker of colorectal cancer. J Clin Endocrinol Metab 2010; 95:1717-1725.

67. Mandel JS, Bond JH, Church TR, et al. Reducing mortality from colorectal cancer by screening for fecal occult blood. Minnesota Colon Cancer Control Study. N Engl J Med 1993; 
328:1365-1371

68. Kronborg O, Fenger C, Olsen J, Jørgensen OD, Søndergaard O. Randomised study of screening for colorectal cancer with faecal-occult-blood test. Lancet 1996;348:1467-1471.

69. Faivre J, Dancourt V, Lejeune C, et al. Reduction in colorectal cancer mortality by fecal occult blood screening in a French controlled study. Gastroenterology 2004;126:1674-1680.

70. Kuipers EJ, Rösch T, Bretthauer M. Colorectal cancer screening: optimizing current strategies and new directions. Nat Rev Clin Oncol 2013;10:130-142.

71. Valori R, Rey JF, Atkin WS, et al. European guidelines for quality assurance in colorectal cancer screening and diagnosis. first edition: quality assurance in endoscopy in colorectal cancer screening and diagnosis. Endoscopy 2012;44 Suppl 3:SE88-SE105.

72. Ahlquist DA, Harrington JJ, Burgart LJ, Roche PC. Morphometric analysis of the "mucocellular layer" overlying colorectal cancer and normal mucosa: relevance to exfoliation and stool screening. Hum Pathol 2000;31:51-57.

73. Zou H, Harrington JJ, Klatt KK, Ahlquist DA. A sensitive method to quantify human long DNA in stool: relevance to colorectal cancer screening. Cancer Epidemiol Biomarkers Prev 2006;15:1115-1119.

74. Wilschut JA, Habbema JD, van Leerdam ME, et al. Fecal occult blood testing when colonoscopy capacity is limited. J Natl Cancer Inst 2011;103:1741-1751.

75. Young GP, Symonds EL, Allison JE, et al. Advances in fecal occult blood tests: the FIT revolution. Dig Dis Sci 2015;60: 609-622

76. Morikawa T, Kato J, Yamaji Y, Wada R, Mitsushima T, Shiratori Y. A comparison of the immunochemical fecal occult blood test and total colonoscopy in the asymptomatic population. Gastroenterology 2005;129:422-428.

77. Gupta AK, Melton LJ 3rd, Petersen GM, et al. Changing trends in the incidence, stage, survival, and screen-detection of colorectal cancer: a population-based study. Clin Gastroenterol Hepatol 2005;3:150-158.

78. Ahlquist DA. Molecular detection of colorectal neoplasia. Gastroenterology 2010;138:2127-2139.

79. Elias H, Hyde DM, Mullens RS, Lambert FC. Colonic adenomas: stereology and growth mechanisms. Dis Colon Rectum 1981;24:331-342.

80. Loktionov A, O’Neill IK, Silvester KR, Cummings JH, Middleton SJ, Miller R. Quantitation of DNA from exfoliated colonocytes isolated from human stool surface as a novel noninvasive screening test for colorectal cancer. Clin Cancer Res
1998;4:337-342.

81. Diehl F, Schmidt K, Durkee KH, et al. Analysis of mutations in DNA isolated from plasma and stool of colorectal cancer patients. Gastroenterology 2008;135:489-498.

82. Park SK, Baek HL, Yu J, et al. Is methylation analysis of SFRP2, TFPI2, NDRG4, and BMP3 promoters suitable for colorectal cancer screening in the Korean population? Intest Res 2017; 15:495-501.

83. Chen WD, Han ZJ, Skoletsky J, et al. Detection in fecal DNA of colon cancer-specific methylation of the nonexpressed vimentin gene. J Natl Cancer Inst 2005;97:1 124-1132.

84. Itzkowitz S, Brand R, Jandorf L, et al. A simplified, noninvasive stool DNA test for colorectal cancer detection. Am J Gastroenterol 2008;103:2862-2870.

85. Coppedè F, Lopomo A, Spisni R, Migliore L. Genetic and epigenetic biomarkers for diagnosis, prognosis and treatment of colorectal cancer. World J Gastroenterol 2014;20:943-956.

86. Imperiale TF, Ransohoff DF, Itzkowitz SH, Turnbull BA, Ross ME; Colorectal Cancer Study Group. Fecal DNA versus fecal occult blood for colorectal-cancer screening in an averagerisk population. N Engl J Med 2004;351:2704-2714.

87. Imperiale TF, Ransohoff DF, Itzkowitz SH, et al. Multitarget stool DNA testing for colorectal-cancer screening. N Engl J Med 2014;370:1287-1297.

88. Miyoshi H, Uchida K, Matsuse R, et al. Clinical study of a new fecal occult blood test using a combination assay of hemoglobin and transferrin. Gastroenterol Jpn 1991;26:151-156.

89. Parente F, Marino B, Ilardo A, et al. A combination of faecal tests for the detection of colon cancer: a new strategy for an appropriate selection of referrals to colonoscopy? A prospective multicentre Italian study. Eur J Gastroenterol Hepatol 2012;24:1145-1152.

90. Sheng JQ, Li SR, Su H, et al. Fecal cytology in conjunction with immunofecal occult blood test for colorectal cancer screening. Anal Quant Cytol Histol 2010;32:131-135.

91. Huang Z, Huang D, Ni S, Peng Z, Sheng W, Du X. Plasma microRNAs are promising novel biomarkers for early detection of colorectal cancer. Int J Cancer 2010;127:118-126.

92. Link A, Balaguer F, Shen Y, et al. Fecal MicroRNAs as novel biomarkers for colon cancer screening. Cancer Epidemiol Biomarkers Prev 2010;19:1766-1774.

93. Koga Y, Yasunaga M, Takahashi A, et al. MicroRNA expression profiling of exfoliated colonocytes isolated from feces for colorectal cancer screening. Cancer Prev Res (Phila) 2010; 3:1435-1442.

94. Li JM, Zhao RH, Li ST, et al. Down-regulation of fecal miR- 
143 and miR-145 as potential markers for colorectal cancer. Saudi Med J 2012;33:24-29.

95. Ascierto PA, Kirkwood JM, Grob JJ, et al. The role of BRAF V600 mutation in melanoma. J Transl Med 2012;10:85.

96. Yuan ZX, Wang XY, Qin QY, et al. The prognostic role of BRAF mutation in metastatic colorectal cancer receiving anti-EGFR monoclonal antibodies: a meta-analysis. PLoS One 2013; 8:e65995.

97. Forbes SA, Bhamra G, Bamford S, et al. The catalogue of somatic mutations in cancer (COSMIC). Curr Protoc Hum Genet 2008;57:10.11.1-10.11.26.

98. Li Y, Li W. BRAF mutation is associated with poor clinicopathological outcomes in colorectal cancer: a meta-analysis. Saudi J Gastroenterol 2017;23:144-149.

99. Gavin PG, Colangelo LH, Fumagalli D, et al. Mutation profiling and microsatellite instability in stage II and III colon cancer: an assessment of their prognostic and oxaliplatin predictive value. Clin Cancer Res 2012;18:6531-6541.

100. Lochhead P, Kuchiba A, Imamura Y, et al. Microsatellite instability and BRAF mutation testing in colorectal cancer prognostication. J Natl Cancer Inst 2013;105:1151-1156.

101. Sepulveda AR, Hamilton SR, Allegra CJ, et al. Molecular biomarkers for the evaluation of colorectal cancer: guideline from the American society for Clinical Pathology, College of American Pathologists, Association for Molecular Pathology, and American Society of Clinical Oncology. Arch Pathol Lab Med 2017;141:625-657.

102. Tiwari AK, Roy HK, Lynch HT. Lynch syndrome in the 21st century: clinical perspectives. QJM 2016;109:151-158.

103. Ward R, Meagher A, Tomlinson I, et al. Microsatellite instability and the clinicopathological features of sporadic colorectal cancer. Gut 2001;48:821-829.

104. Graham DM, Coyle VM, Kennedy RD, Wilson RH. Molecular subtypes and personalized therapy in metastatic colorectal cancer. Curr Colorectal Cancer Rep 2016;12:141-150.

105. Lynch HT, de la Chapelle A. Hereditary colorectal cancer. N Engl J Med 2003;348:919-932.

106. Kane MF, Loda M, Gaida GM, et al. Methylation of the hMLH1 promoter correlates with lack of expression of hMLH1 in sporadic colon tumors and mismatch repair-defective human tumor cell lines. Cancer Res 1997;57:808-811.

107. Sepulveda AR, Hamilton SR, Allegra CJ, et al. Molecular biomarkers for the evaluation of colorectal cancer: guideline from the American society for clinical pathology, college of American pathologists, association for molecular pathology, and American society of clinical oncology. J Mol Diagn 2017;
19:187-225.

108. Imai K, Yamamoto H. Carcinogenesis and microsatellite instability: the interrelationship between genetics and epigenetics. Carcinogenesis 2008;29:673-680.

109. Carethers JM, Jung BH. Genetics and genetic biomarkers in sporadic colorectal cancer. Gastroenterology 2015;149:11771190.

110. Guastadisegni C, Colafranceschi M, Ottini L, Dogliotti E. Microsatellite instability as a marker of prognosis and response to therapy: a meta-analysis of colorectal cancer survival data. Eur J Cancer 2010;46:2788-2798.

111. Toyota M, Ahuja N, Ohe-Toyota M, Herman JG, Baylin SB, Issa JP. CpG island methylator phenotype in colorectal cancer. Proc Natl Acad Sci U S A 1999;96:8681-8686.

112. Nowak JA, Hornick JL. Molecular evaluation of colorectal adenocarcinoma: current practice and emerging concepts. Surg Pathol Clin 2016;9:427-439.

113. Nosho K, Irahara N, Shima K, et al. Comprehensive biostatistical analysis of $\mathrm{CpG}$ island methylator phenotype in colorectal cancer using a large population-based sample. PLoS One 2008;3:e3698.

114. Ogino S, Cantor M, Kawasaki T, et al. CpG island methylator phenotype (CIMP) of colorectal cancer is best characterised by quantitative DNA methylation analysis and prospective cohort studies. Gut 2006;55:1000-1006.

115. Lee S, Cho NY, Yoo EJ, Kim JH, Kang GH. CpG island methylator phenotype in colorectal cancers: comparison of the new and classic CpG island methylator phenotype marker panels. Arch Pathol Lab Med 2008;132:1657-1665.

116. Jia M, Gao X, Zhang Y, Hoffmeister M, Brenner H. Different definitions of $\mathrm{CpG}$ island methylator phenotype and outcomes of colorectal cancer: a systematic review. Clin Epigenetics 2016;8:25.

117. Narayan S, Roy D. Role of APC and DNA mismatch repair genes in the development of colorectal cancers. Mol Cancer 2003;2:41.

118. Chen TH, Chang SW, Huang CC, et al. The prognostic significance of APC gene mutation and miR-21 expression in advanced-stage colorectal cancer. Colorectal Dis 2013;15:13671374.

119. Lech G, Słotwiński R, Słodkowski M, Krasnodębski IW. Colorectal cancer tumour markers and biomarkers: recent therapeutic advances. World J Gastroenterol 2016;22:1745-1755.

120. Westra JL, Schaapveld M, Hollema H, et al. Determination of TP53 mutation is more relevant than microsatellite instability status for the prediction of disease-free survival in adju- 
vant-treated stage III colon cancer patients. J Clin Oncol 2005; 23:5635-5643.

121. Allegra CJ, Paik S, Colangelo LH, et al. Prognostic value of thymidylate synthase, Ki-67, and p53 in patients with Dukes' B and C colon cancer: a National Cancer Institute-National Surgical Adjuvant Breast and Bowel Project collaborative study. J Clin Oncol 2003;21:241-250.

122. Russo A, Bazan V, Iacopetta B, et al. The TP53 colorectal cancer international collaborative study on the prognostic and predictive significance of p53 mutation: influence of tumor site, type of mutation, and adjuvant treatment. J Clin Oncol 2005;23:7518-7528.

123. Petersen S, Thames HD, Nieder C, Petersen C, Baumann M. The results of colorectal cancer treatment by p53 status: treatment-specific overview. Dis Colon Rectum 2001;44:322-333.

124. Popat S, Chen Z, Zhao D, et al. A prospective, blinded analysis of thymidylate synthase and p53 expression as prognostic markers in the adjuvant treatment of colorectal cancer. Ann Oncol 2006;17:1810-1817.

125. Xu Y, Pasche B. TGF-beta signaling alterations and susceptibility to colorectal cancer. Hum Mol Genet 2007;16 Spec No 1:R14-R20.

126. Nikolic A, Kojic S, Knezevic S, Krivokapic Z, Ristanovic M, Radojkovic D. Structural and functional analysis of SMAD4 gene promoter in malignant pancreatic and colorectal tissues: detection of two novel polymorphic nucleotide repeats. Cancer Epidemiol 2011;35:265-271.

127. Riggins GJ, Kinzler KW, Vogelstein B, Thiagalingam S. Frequency of Smad gene mutations in human cancers. Cancer Res 1997;57:2578-2580.

128. Salovaara R, Roth S, Loukola A, et al. Frequent loss of SMAD4/ DPC4 protein in colorectal cancers. Gut 2002;51:56-59.

129. Voorneveld PW, Jacobs RJ, Kodach LL, Hardwick JC. A metaanalysis of SMAD4 immunohistochemistry as a prognostic marker in colorectal cancer. Transl Oncol 2015;8:18-24.

130. Locker GY, Hamilton S, Harris J, et al. ASCO 2006 update of recommendations for the use of tumor markers in gastrointestinal cancer. J Clin Oncol 2006;24:5313-5327.

131. Renehan AG, Egger M, Saunders MP, O’Dwyer ST. Impact on survival of intensive follow up after curative resection for colorectal cancer: systematic review and meta-analysis of randomised trials. BMJ 2002;324:813.

132. Rosen M, Chan L, Beart RW Jr, Vukasin P, Anthone G. Followup of colorectal cancer: a meta-analysis. Dis Colon Rectum 1998;41:1116-1126.

133. Li Destri G, Rubino AS, Latino R, et al. Preoperative carcino- embryonic antigen and prognosis of colorectal cancer. An independent prognostic factor still reliable. Int Surg 2015; 100:617-625.

134. Park YJ, Park KJ, Park JG, Lee KU, Choe KJ, Kim JP. Prognostic factors in 2230 Korean colorectal cancer patients: analysis of consecutively operated cases. World J Surg 1999;23:721-726.

135. Nordlinger B, Guiguet M, Vaillant JC, et al. Surgical resection of colorectal carcinoma metastases to the liver: a prognostic scoring system to improve case selection, based on 1568 patients. Association Française de Chirurgie. Cancer 1996;77: 1254-1262.

136. Fong Y, Fortner J, Sun RL, Brennan MF, Blumgart LH. Clinical score for predicting recurrence after hepatic resection for metastatic colorectal cancer: analysis of 1001 consecutive cases. Ann Surg 1999;230:309-318.

137. Grivennikov SI, Greten FR, Karin M. Immunity, inflammation, and cancer. Cell 2010;140:883-899.

138. Zahorec R. Ratio of neutrophil to lymphocyte counts: rapid and simple parameter of systemic inflammation and stress in critically ill. Bratisl Lek Listy 2001;102:5-14.

139. Smith RA, Bosonnet L, Raraty M, et al. Preoperative plateletlymphocyte ratio is an independent significant prognostic marker in resected pancreatic ductal adenocarcinoma. Am J Surg 2009;197:466-472.

140. Shimada H, Takiguchi N, Kainuma O, et al. High preoperative neutrophil-lymphocyte ratio predicts poor survival in patients with gastric cancer. Gastric Cancer 2010;13:170-176.

141. Mano Y, Shirabe K, Yamashita Y, et al. Preoperative neutrophil-to-lymphocyte ratio is a predictor of survival after hepatectomy for hepatocellular carcinoma: a retrospective analysis. Ann Surg 2013;258:301-305.

142. Li MX, Liu XM, Zhang XF, et al. Prognostic role of neutrophilto-lymphocyte ratio in colorectal cancer: a systematic review and meta-analysis. Int J Cancer 2014;134:2403-2413.

143. Tsai PL, Su WJ, Leung WH, Lai CT, Liu CK. Neutrophil-lymphocyte ratio and CEA level as prognostic and predictive factors in colorectal cancer: a systematic review and metaanalysis. J Cancer Res Ther 2016;12:582-589.

144. Tang H, Li B, Zhang A, Lu W, Xiang C, Dong J. Prognostic significance of neutrophil-to-lymphocyte ratio in colorectal liver metastasis: a systematic review and meta-analysis. PLoS One 2016;11:e0159447.

145. Schwarzenbach H, Stoehlmacher J, Pantel K, Goekkurt E. Detection and monitoring of cell-free DNA in blood of patients with colorectal cancer. Ann N Y Acad Sci 2008;1137: 190-196. 
146. Wang JY, Hsieh JS, Chang MY, et al. Molecular detection of APC, K- ras, and p53 mutations in the serum of colorectal cancer patients as circulating biomarkers. World J Surg 2004; 28:721-726.

147. Xu JM, Liu XJ, Ge FJ, et al. KRAS mutations in tumor tissue and plasma by different assays predict survival of patients with metastatic colorectal cancer. J Exp Clin Cancer Res 2014; 33:104.

148. Sinicrope FA, Mahoney MR, Yoon HH, et al. Analysis of Molecular Markers by Anatomic Tumor Site in Stage III Colon Carcinomas from Adjuvant Chemotherapy Trial NCCTG N0147 (Alliance). Clin Cancer Res 2015;21:5294-5304.

149. Marais R, Light Y, Paterson HF, Marshall CJ. Ras recruits Raf1 to the plasma membrane for activation by tyrosine phosphorylation. EMBO J 1995;14:3136-3145.

150. De Roock W, Claes B, Bernasconi D, et al. Effects of KRAS, BRAF, NRAS, and PIK3CA mutations on the efficacy of cetuximab plus chemotherapy in chemotherapy-refractory metastatic colorectal cancer: a retrospective consortium analysis. Lancet Oncol 2010;11:753-762.

151. Peeters M, Price TJ, Cervantes A, et al. Randomized phase III study of panitumumab with fluorouracil, leucovorin, and irinotecan (FOLFIRI) compared with FOLFIRI alone as second-line treatment in patients with metastatic colorectal cancer. J Clin Oncol 2010;28:4706-4713.

152. Van Cutsem E, Köhne CH, Láng I, et al. Cetuximab plus irinotecan, fluorouracil, and leucovorin as first-line treatment for metastatic colorectal cancer: updated analysis of overall survival according to tumor KRAS and BRAF mutation status. J Clin Oncol 2011;29:2011-2019.

153. Bokemeyer C, Bondarenko I, Hartmann JT, et al. Efficacy according to biomarker status of cetuximab plus FOLFOX-4 as first-line treatment for metastatic colorectal cancer: the OPUS study. Ann Oncol 2011;22:1535-1546.

154. Sepulveda AR, Hamilton SR, Allegra CJ, et al. Molecular biomarkers for the evaluation of colorectal cancer: guideline from the American society for clinical pathology, college of American pathologists, association for molecular pathology, and the American society of clinical oncology. J Clin Oncol 2017;35:1453-1486.

155. Rowland A, Dias MM, Wiese MD, et al. Meta-analysis of BRAF mutation as a predictive biomarker of benefit from anti-EGFR monoclonal antibody therapy for RAS wild-type metastatic colorectal cancer. Br J Cancer 2015;112:1888-1894.
156. Michael JV, Wurtzel JG, Goldfinger LE. Regulation of H-Rasdriven MAPK signaling, transformation and tumorigenesis, but not PI3K signaling and tumor progression, by plasma membrane microdomains. Oncogenesis 2016;5:e228.

157. Sartore-Bianchi A, Martini M, Molinari F, et al. PIK3CA mutations in colorectal cancer are associated with clinical resistance to EGFR-targeted monoclonal antibodies. Cancer Res 2009;69:1851-1857.

158. Perrone F, Lampis A, Orsenigo M, et al. PI3KCA/PTEN deregulation contributes to impaired responses to cetuximab in metastatic colorectal cancer patients. Ann Oncol 2009;20: 84-90.

159. Huang L, Liu Z, Deng D, et al. Anti-epidermal growth factor receptor monoclonal antibody-based therapy for metastatic colorectal cancer: a meta-analysis of the effect of PIK3CA mutations in KRAS wild-type patients. Arch Med Sci 2014; 10:1-9.

160. Karapetis CS, Jonker D, Daneshmand M, et al. PIK3CA, BRAF, and PTEN status and benefit from cetuximab in the treatment of advanced colorectal cancer: results from NCIC CTG/AGITG CO.17. Clin Cancer Res 2014;20:744-753.

161. Algra AM, Rothwell PM. Effects of regular aspirin on longterm cancer incidence and metastasis: a systematic comparison of evidence from observational studies versus randomised trials. Lancet Oncol 2012;13:518-527.

162. Din FV, Theodoratou E, Farrington SM, et al. Effect of aspirin and NSAIDs on risk and survival from colorectal cancer. Gut 2010;59:1670-1679.

163. Liao X, Lochhead P, Nishihara R, et al. Aspirin use, tumor PIK3CA mutation, and colorectal-cancer survival. N Engl J Med 2012;367:1596-1606.

164. Diehl F, Schmidt K, Choti MA, et al. Circulating mutant DNA to assess tumor dynamics. Nat Med 2008;14:985-990.

165. Zitt M, Müller HM, Rochel M, et al. Circulating cell-free DNA in plasma of locally advanced rectal cancer patients undergoing preoperative chemoradiation: a potential diagnostic tool for therapy monitoring. Dis Markers 2008;25:159-165.

166. Agostini M, Pucciarelli S, Enzo MV, et al. Circulating cell-free DNA: a promising marker of pathologic tumor response in rectal cancer patients receiving preoperative chemoradiotherapy. Ann Surg Oncol 2011;18:2461-2468.

167. Leon SA, Shapiro B, Sklaroff DM, Yaros MJ. Free DNA in the serum of cancer patients and the effect of therapy. Cancer Res 1977;37:646-650. 